\title{
Driving force for shape memory effect of polymers
}

\author{
Achraf Kallel $^{1} \oplus$ - Abir Ben Abdallah ${ }^{2,3} \cdot$ Fehmi Gamaoun $^{3,4} \cdot$ Sedigheh Farzaneh $^{2} \cdot$ Hachmi BenDaly $^{3} \cdot$ \\ Joseph Fitoussi ${ }^{2} \cdot$ Abbas Tcharkhtchi $^{2}$
}

\begin{abstract}
In this study, we aim to evaluate the shape memory effect of a Poly (Caprolactone) (PCL) (40\%) and a Styrene-ButadieneStyrene (SBS) (60\%) blend. Shape memory cycle tests are performed at different temperatures to detect the best recovery rate. Under appropriate temperature, the blend recovers substantially its original shape. To study the recovery rate evolution, multi cycle tests are realized with controlled temperature. The results indicate that the shape memory effect growths when the number of cycle increases. The stored energy acts as a driving force to bring the polymer to its permanent shape after each loading cycle. Then, an original method is proposed to measure the stress-strain evolution during the recovery. With a variable temperature, no standard test can follow the stress-strain evolution. This test is needed to validate the behavior model.
\end{abstract}

Keywords Shape memory polymers · Blend PCL /SBS $\cdot$ Shape memory effect $\cdot$ Driving force

\section{Introduction}

The interest of the shape memory property in polymers has increased in last decade with a wide range of academic and industrial fields thanks to their ability to change from a temporary shape to their permanent one under a stimulus. Refer to references [1-3], there are three types of stimuli for SMPs, thermo- (both heating and cooling, direct and indirect), chemo- (including water) and photo- (without much heat). In this study, heating-responsive polymer is used. The cycle process consists of a deformation at high temperature, cooling (fixing step), releasing the stress and finally reheating (recovery step) [4-6]. This cycle process may be performed sometimes without the relaxation step. Compared with the Shape Memory Alloys (SMAs) [7], SMPs have the benefits of low cost, light weight, high recoverability and

Achraf Kallel

achraf.kallel@devinci.fr

1 Léonard de Vinci Pôle Universitaire, Research Center, 92916 Paris La Défense, France

2 Laboratoire PIMM, CNRS, HESAM Université, Arts et Métiers ParisTech, CnamParis, France

3 Laboratoire Mécanique de Sousse, Université de Sousse, ENISO, Sousse, Tunisia

4 Department of Mechanical Engineering, College of Engineering, King Khalid University, Abha, Saudi Arabia good processing capacity. They are useful in a lot of domains as medical and biological devices [8, 9], smart textile [10, $11]$, tubing and actuating materials and packaging components [12-14]. Two different phases (hard and soft) in the structure of SMP are needed to set off the shape memory effect (SME). Each phase in the immiscible blend has a specific mechanical property. The hard segments represent the crosslinks (chemical or physical). They ensure shape stability and the determination of the permanent shape [16]. The soft segments (switching segments) are formed by flexible chains at high temperature. These chains are sensitive to the stimulus. They allow to set the temporary shape and to ensure the shape change [17]. At the end of the recovery test, most polymers regain only a certain percentage of their initial shape. This denotes the Partial Shape Memory Effect (PSME) concept. Yet, all polymers present a shape memory capacity. Depending on the programming strain, programming temperature and the polymer structure, some of them belong to total shape memory polymer family and the others still with a partial shape memory effect. Recent studies on SME [4-6] have indicated that SMPs could recuperate their permanent shape without recovering their initial properties. The authors performed tensile tests and DMA (Dynamic Mechanical Analyzer) tests on virgin and $100 \%$ recovered samples of Poly (Urethane) PU. Results revealed that the PU at the end of the shape memory tests regains $100 \%$ of its initial form without recovering all its physical properties, 
like the glass transition temperature, the Young modulus, the heat expansion coefficient and the free volume fraction. This outcome could be explained by irreversible microstructure changes such as micro sized fracture inside of the polymer as reported in [21]. These microstructure changes can induce volume micro-change that cannot be regained after the recovery test. The macro-change of the volume could be measured contrary to the micro-change that cannot be accurately measured and which is usually neglected [6] The relationship between the SME and the micro-change in the polymer structure has been recently explained [5]. It has been demonstrated that during the cooling step some residual stresses are stored in the structure [4-6]. The energy stored in the structure acts as the driving force that could be responsible for the SMP of the polymer. In the present work, this driving force is particularly investigated. In order to show the origin of this driving force, relationship between the recovery rate and the residual stresses stored in the polymer during its deformation is determined. To evaluate this driving force one original method will be presented.

\section{Materials and methods}

A mixture of Poly (Caprolactone) (PCL) and StyreneButadiene-Styrene (SBS) is used. The PCL is a semi-crystalline biodegradable thermoplastic mainly used in the implementation of special polyurethanes and polyamides. It is obtained by Caprolactone ring-opening polymerization. The PCL used for this study is PCL CAPA 6800 and is supplied by Perstrop Limited UK with a density of $1140 \mathrm{~kg} / \mathrm{m}^{3}$. Its glass transition temperature $\mathrm{T}_{\mathrm{g}}$ and its melting temperature $T_{m}$ are respectively $-50^{\circ} \mathrm{C}$ and $60^{\circ} \mathrm{C}$ [19]. The SBS, provided by the company Sinopec Group, is an amorphous copolymer composed by poly (butadiene) rubber (PB) and thermoplastic polystyrene (PS). Its main chain is formed by three segments, PB in the middle and PS in both sides [20]. Its $\mathrm{T}_{\mathrm{g}}$ is almost -80 ${ }^{\circ} \mathrm{C}$. The PCL and SBS homogeneous mixture are blended by extrusion through a twin screw Brabender extruder machine (Brabender, Duidburg, Germany) in the temperature range between $150^{\circ} \mathrm{C}$ and $180^{\circ} \mathrm{C}$. The extruded pellets of the blend have been introduced in an injection molding machine to obtain the final shape of specimens. All tests were carried out on specimens with the following dimensions: the gage length $=30 \mathrm{~mm}$, the width $=4 \mathrm{~mm}$ and the thickness $=2$ $\mathrm{mm}$ according to the norm ISO 527-2 [24]. When the PCL proportion is between $30 \%$ and $50 \%$, the blend shows a better SME [22]. In addition, one has shown in a former work [23] that the SBS/PCL blend exhibit a total shape memory effect when the PCL proportion is equal to $40 \%$. The shape memory test consists of five steps: (1) heating the sample;

(2) tensile test while keeping the same heating temperature;

(3) fixing the deformed shape by cooling down the sample to the room temperature (4) unloading the sample to zero stress and then recording the strain and (5) heating up again the unloaded sample and then recording the strain (recovery test).The recovery rate, which represents the capacity of the SMP to recuperate its permanent shape, is given by following equation:

$R_{r}(\%)=\frac{L_{u}-L_{f}}{L_{u}-L_{i}} * 100$

The fixing rate, which represents the capacity of the SMP to maintain a temporary shape, is determined as follows:

$R_{f}(\%)=\frac{L_{u}}{L_{m}} * 100$

Where $L_{i}$ is the initial sample length, $L_{m}$ is the length after $100 \%$ of deformation, $L_{u}$ is the length after a tensile test without stress (jaws are release), and $L_{f}$ is the length after recovery.

Shape memory tests are performed on blend with different PCL proportion. The values of $R_{f}$ and $R_{r}$ are determined for each blend. The results are recapitulated in Table 1.

For this study, the blend with $40 \%$ of PCL and $60 \%$ of SBS is chosen because it presents $100 \%$ of recovery. This blend will be used in the following sections.

\section{Thermal proprieties}

To determine the Tg, DMA tests are carried out using DMA Q800 TA Instruments. The tests are performed at the following conditions: $1 \mathrm{~Hz}$ frequency; temperature range between $-100{ }^{\circ} \mathrm{C}$ and $70^{\circ} \mathrm{C}$ and heating rate $3^{\circ} \mathrm{C} / \mathrm{min}$. Figure 1 illustrates the DMA diagrams of the pure PCL, the pure SBS and the blend of $40 \%$ PCL/60\% SBS.

A TA Instruments DSC-Q10 V9.0 Build 275-type Differential Scanning Calorimeter is used to determine the $T_{m}$ of the polymer. Specimens are cooled with liquid nitrogen

Table $1 R_{f}$ and $R_{r}$ for different blend [15]

\begin{tabular}{lllll}
\hline PCL $(\%)$ & SBS $(\%)$ & Blends & $R_{f}(\%)$ & $R_{r}(\%)$ \\
\hline 0 & 100 & pure SBS & 61.7 & 99.6 \\
10 & 90 & PCL(10\%)/SBS(90\%) & 46.6 & 98.6 \\
20 & 80 & PCL(20\%)/SBS(80\%) & 53.9 & 98.7 \\
30 & 70 & PCL(30\%)/SBS(70\%) & 54.6 & 97.6 \\
40 & 60 & PCL(40\%)/SBS(60\%) & 74.5 & 100 \\
50 & 50 & PCL(50\%)/SBS(50\%) & 89.5 & 97.5 \\
60 & 40 & PCL(60\%)/SBS(40\%) & 90.8 & 77.7 \\
70 & 30 & PCL(70\%)/SBS(30\%) & 87.8 & 63.1 \\
80 & 20 & PCL(80\%)/SBS(20\%) & 94.3 & 59.9 \\
90 & 10 & PCL(90\%)/SBS(10\%) & 97.3 & 52.3 \\
100 & 0 & pure PCL & 98.6 & 36.1 \\
\hline
\end{tabular}


Fig. 1 DMA Results on pure PCL, pure SBS and the blend

Fig. 2 Results of DSC tests on pure PCL a, pure SBS $\mathbf{b}$ and the blend.


from room temperature to $-80{ }^{\circ} \mathrm{C}$ and then heated up to $80{ }^{\circ} \mathrm{C}$ with cooling and heating rate of $3{ }^{\circ} \mathrm{C} / \mathrm{min}$. Figure 2 illustrates the DSC diagrams of the pure PCL, the pure SBS and the blend of $40 \%$ PCL/60\% SBS.

Table 2 illustrate the thermal properties of studied materials. The pure PCL presents a $\mathrm{T}_{\mathrm{g}}$ of $-40.1{ }^{\circ} \mathrm{C}$ and a $T_{m}$ of $60{ }^{\circ} \mathrm{C}$. The pure SBS presents a $T_{\alpha}$ of $-76^{\circ} \mathrm{C}$. Since it is an elastomeric polymer, no melting point is recorded. Accordingly, the blends show two glass transitions temperatures but only one $T_{m}$ close to the melting point of PCL. The presence of two distinct glass transition temperatures confirms the immiscibility of the (SBS/PCL) blend.

\section{Morphological proprieties}

SEM observations were performed using a Hitachi 4800 type machine with a voltage of $5 \mathrm{~V}$ to $10 \mathrm{~V}$ to characterize the morphology of the mixture and analyze the PCL / SBS interface.

Table 2 Thermal properties of PCL, SBS and blend

\begin{tabular}{llll}
\hline & $T_{m}\left({ }^{\circ} \mathrm{C}\right)$ & $\mathrm{T}_{\mathrm{g}_{-} 1}\left({ }^{\circ} \mathrm{C}\right)$ & $\mathrm{T}_{\mathrm{g}_{\_} 2}\left({ }^{\circ} \mathrm{C}\right)$ \\
\hline PCL & 60 & & -40.1 \\
SBS & - & -76 & \\
$40 \%$ PCL/60\% SBS & 58.9 & -80.7 & -39.7 \\
\hline
\end{tabular}


Fig. 3 SME images of the $60 \%$ SBS and $40 \%$ PCL blend
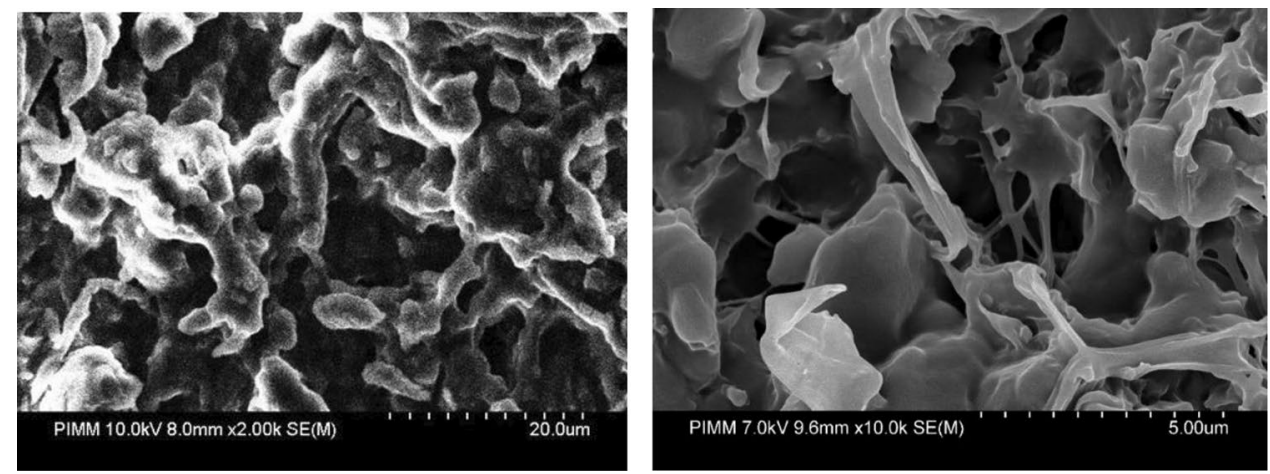

Fig. 4 Tensile tests of SBS / PCL blend at different temperatures

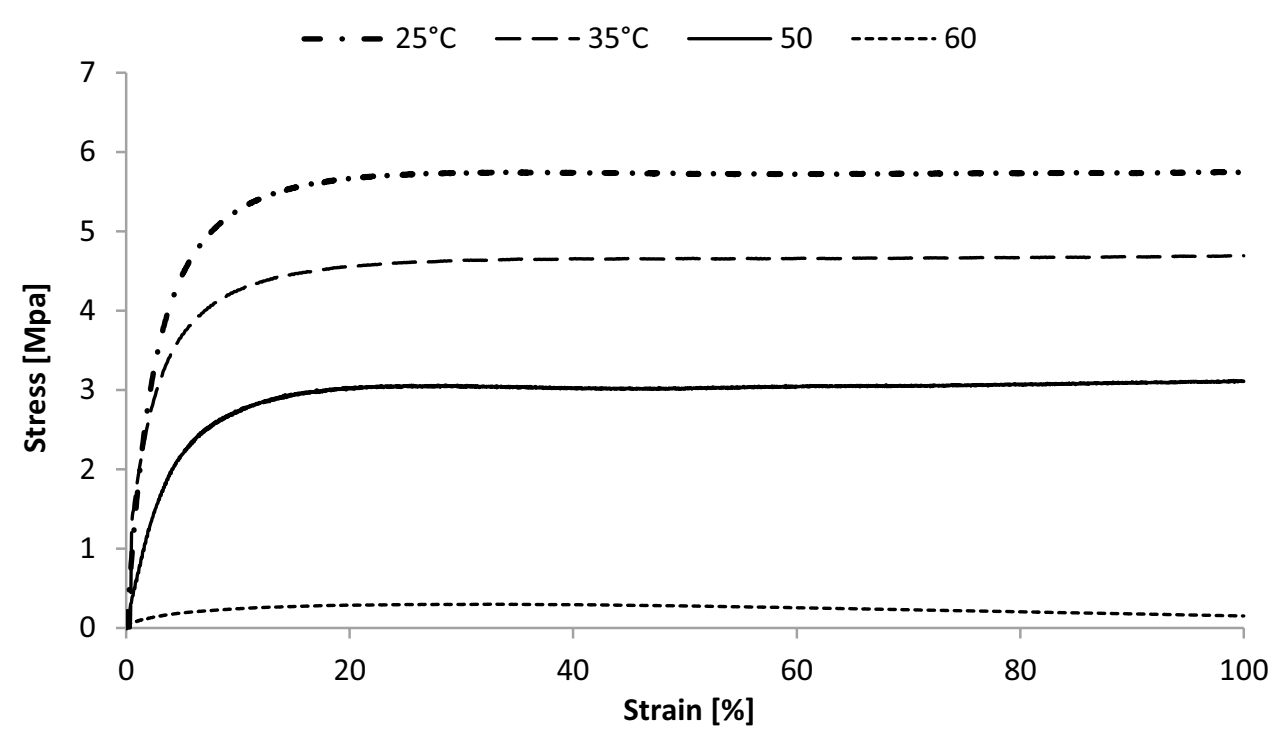

Before analyzing them with SEM, the samples were cut transversely in situ in a liquid nitrogen bath, then metallized. According to SEM observations in Fig. 3, the blend presents two separate regions; bright and dark. The bright zones correspond to SBS phase and the dark ones corresponds to PCL phase. This confirms the intrinsic immiscibility between the SBS and the PCL in the blend. This outcome is in accordance with the work of Zhang et al. [20]. This result confirms DMA curves showing two different glass transition temperatures: the lowest corresponds to the soft phase (SBS) and the highest corresponds to the hard one (PCL). Since the amount of PCL is high (40\%), it does not form a dispersed and discontinuous phase in the SBS matrix $(60 \%)$. The co-continuous morphology which is associated to the interpenetration of the two immiscible polymers could lead to a certain compatibility. This phase continuity indicate that the two polymers are compatible despite their immiscibility.

\section{Mechanical properties}

The stress-strain tests are realized by a uniaxial-tensile loading Instron 5566-type machine with a load cell of $1 \mathrm{kN}$ at room temperature, according to the standard NF ISO 6239 [18]. Results are illustrated in Fig. 4 and Table 3. These results clearly show the influence of temperature on mechanical properties. The stress at $100 \%$ of strain and the Young modulus decrease with the temperature growth. The stress drops significantly when the temperature rises from $50{ }^{\circ} \mathrm{C}$ to $60^{\circ} \mathrm{C}$. At 60 ${ }^{\circ} \mathrm{C}$, the sample presents a weak mechanical behavior (Fig. 4). Indeed, at this temperature, the PCL reaches its melting point. The tensile curves indicate also that the Young modulus goes down from $174 \mathrm{MPa}$ to $7 \mathrm{MPa}$ by increasing the temperature respectively from $25^{\circ} \mathrm{C}$ to $60^{\circ} \mathrm{C}$. We can note that the

Table 3 Young modulus and stress at $100 \%$ of strain at different temperature

\begin{tabular}{lll}
\hline$T\left({ }^{\circ} \mathrm{C}\right)$ & Modulus (MPa) & $\begin{array}{l}\text { Stress at } \\
100 \% \text { strain } \\
(\mathrm{MPa})\end{array}$ \\
\hline 25 & 174 & 5.7 \\
35 & 103 & 4.7 \\
50 & 66 & 3.1 \\
60 & 7 & 0.3 \\
\hline
\end{tabular}




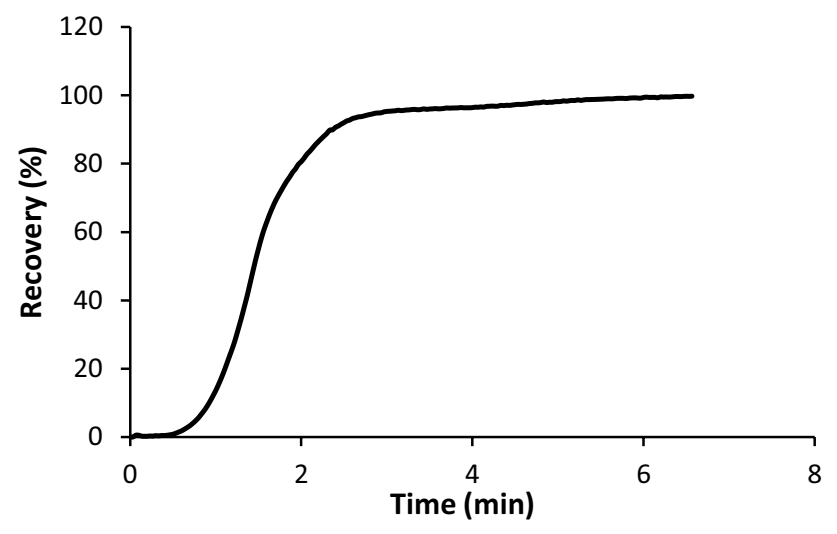

Fig. 5 Evolution of recovery rate

thresholds (yield point) which separate the elastic and plastic areas are between 5 and $10 \%$ of strain $(\varepsilon)$. In the plastic region, the curves are relatively linear; i.e., the plastic deformation has the same mechanism at different temperatures.

\section{Results and discussions}

\section{Recovery and mono shape memory tests}

According to the thermal properties of the $40 \% \mathrm{PCL} /$ $60 \%$ SBS blend, shape memory test is carried out at the following conditions: (1) heating the sample up to $50{ }^{\circ} \mathrm{C}$; (2) extending to the strain of $100 \%$ with a rate of $6 \mathrm{~mm} /$ min (tensile test); (3) fixing the shape at this deformation by cooling down the sample from $50{ }^{\circ} \mathrm{C}$ to the room temperature with a cooling rate of $3{ }^{\circ} \mathrm{C} / \mathrm{min}$; (4) unloading
Table 4 Recovery tests at different temperatures.

\begin{tabular}{lll}
\hline $\begin{array}{l}\text { Tempera- } \\
\text { ture }\left({ }^{\circ} \mathrm{C}\right)\end{array}$ & $R_{r}(\%)$ & $R_{f}(\%)$ \\
\hline 58 & 98.6 & 94.1 \\
55 & 71.9 & 93.4 \\
40 & 63.6 & 92.5 \\
\hline
\end{tabular}

the sample to zero stress and then recording the strain; and (5) heating up again the unloaded sample at a temperature range between $40{ }^{\circ} \mathrm{C}$ and $60^{\circ} \mathrm{C}$ and then recording the strain (recovery test). During the recovery test, the length of the sample decreases and thanks to the SME, the sample recovers its original shape.

It is important to indicate that the recovery test cannot practically be performed isothermally. Yet, the test is performed with a controlled non-isothermal condition during which the temperature rises with a rate of $1{ }^{\circ} \mathrm{C} / \mathrm{min}$. The recovery mechanism is triggered when heating starts. Once the sample attains the recovery temperature $\left(60{ }^{\circ} \mathrm{C}\right)$, major part of its original shape is already recuperated (80\%), as depicted in Fig. 5.

The recovery test is carried out in a thermal chamber at different temperatures. The results are presented in Fig. 6 and Table 4.

These results show that the sample will require less time to recover its original shape when the temperature is higher. For the (PCL/SBS) blend, $98 \%$ recovery is reached in about 20 min at $58{ }^{\circ} \mathrm{C}$; while only $71.9 \%$ of the initial shape is regained at $55{ }^{\circ} \mathrm{C}$. To reach $100 \%$ of recovery, the sample is heated at the same temperature for longer time or at higher temperature $\left(75^{\circ} \mathrm{C}\right)$ for the same duration $(20 \mathrm{~min})$. The recovery rate rises when the temperature is higher. As the temperature increases, the chains become more flexible and the molecular mobility increases, which facilitates the shape recovery.
Fig. 6 Recovery rate at different temperatures

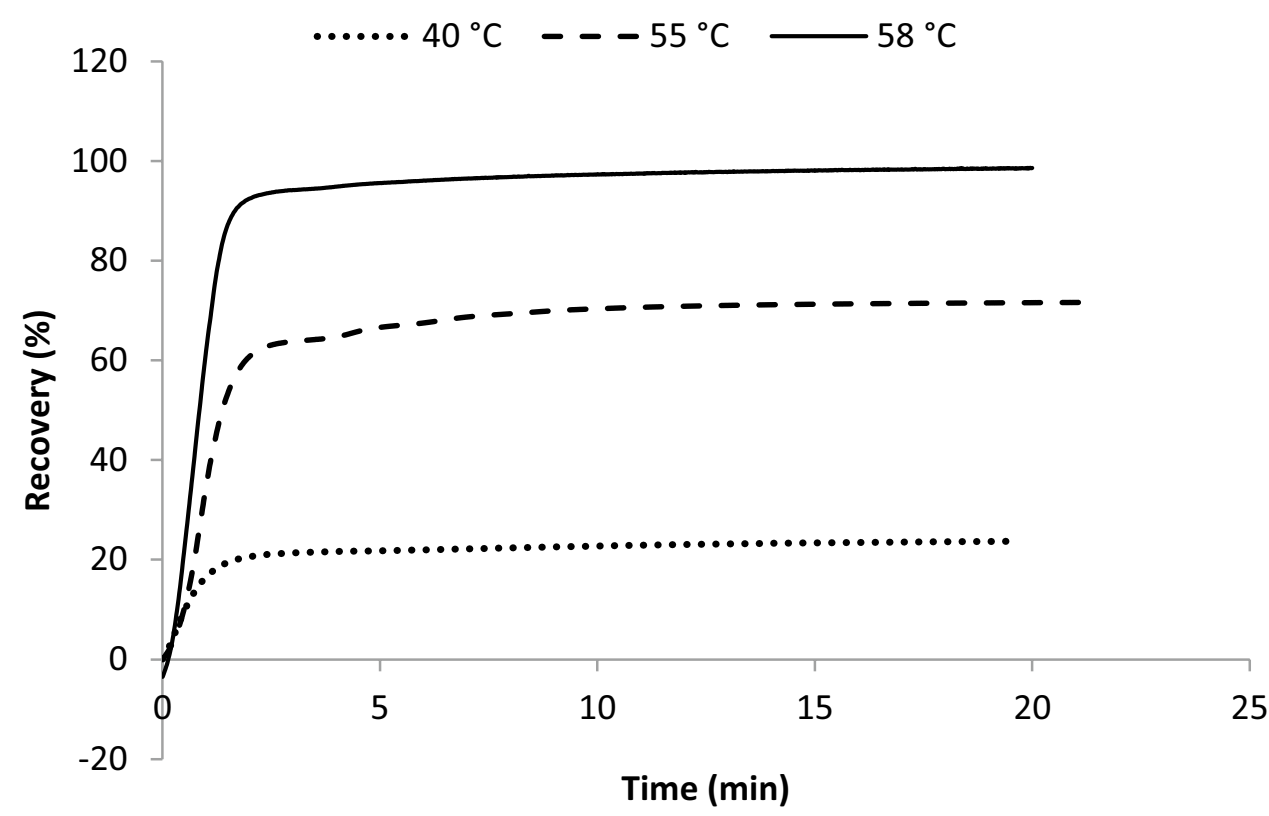


Fig. 7 Tensile test for different cycles

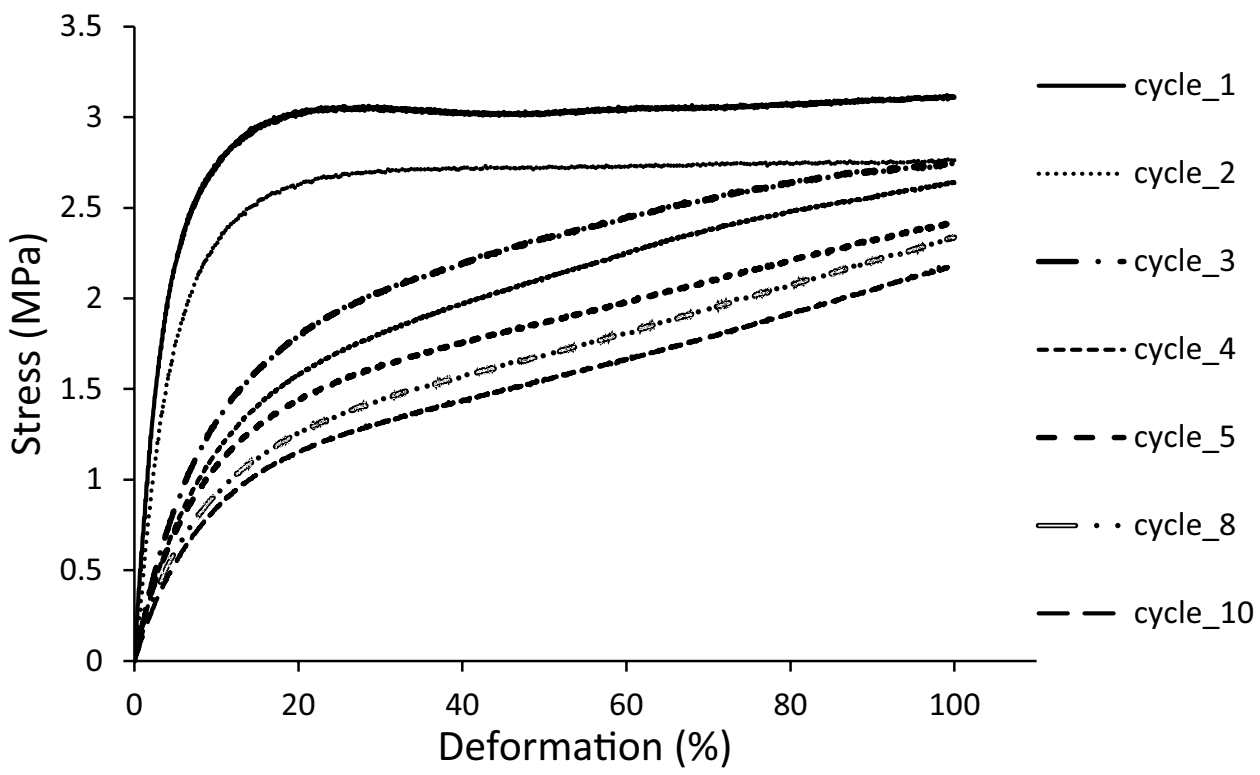

\section{Cyclic shape memory test}

In multi-cycle tests, successive shape memory cycles are performed on the same sample. The results of tensile test at different cycles are presented in Fig. 7. Figure 8 depicts the recovery rate evolution until $18 \mathrm{~min}$ for different cycle numbers. The blend regains $90 \%$ of its initial shape after the first memory test in $18 \mathrm{~min}$. The recovery rate varies until the fifth cycle from which it stabilizes around $92 \%$ until the tenth cycle. The fixing rate falls from $94.6 \%$ in the first cycle to $88 \%$ in the fifth one. Then it remains stable until the tenth cycle. The $R_{f}$ decreases from one cycle to another since the viscoelasticity of the polymer decreases.

For all cycles, tensile tests are performed at $50{ }^{\circ} \mathrm{C}$ and recovery tests at $55{ }^{\circ} \mathrm{C}$. The results are recapitulated in Table 5. The Young modulus decreases sharply from 65.6
$\mathrm{MPa}$ in the first cycle to $12.1 \mathrm{MPa}$ in the tenth cycle. The specimen's maximum stress goes down from $3.1 \mathrm{MPa}$ (cycle1) to 2.1 MPa after 10 shape memory cycles. Although the difference between the recovered shape and the initial shape remains small, the change in mechanical properties is considerable.

The decrease in Young modulus shows that the SMP blend loses stiffness from one cycle to cycle. So even if the mixture returns to its initial shape after each shape memory cycle, it does not retain the same mechanical properties. This outcome is in accordance with the study of Tcharkhtchi et al [5]. They showed from cyclic shape memory tests that PU recovers $100 \%$ of its initial shape without regaining some of its physical properties such as glass transition temperature, tensile modulus and thermal expansion coefficient. To investigate the glass transition temperature evolution, DMA tests
Fig. 8 Recovery rate for different cycles

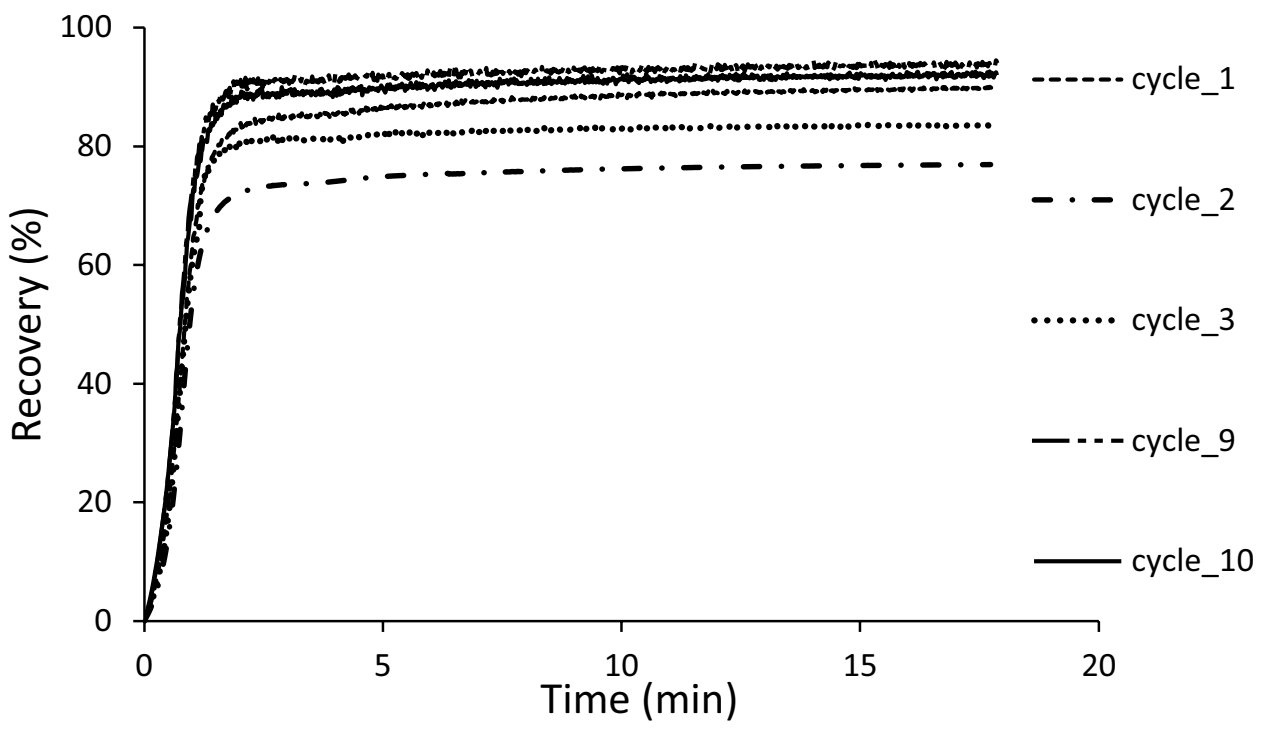


Table 5 Maximal stress, Young modulus, fixing and recovery rate for each cycle after $18 \mathrm{~min}$ of recovery tests

\begin{tabular}{lllll}
\hline $\begin{array}{l}\text { Number of } \\
\text { cycles }\end{array}$ & $\begin{array}{l}\text { Max. stress } \\
(\mathrm{MPa})\end{array}$ & $\begin{array}{l}\text { Young modulus } \\
(\mathrm{MPa})\end{array}$ & $R_{r}(\%)$ & $R_{f}(\%)$ \\
\hline 1 & 3.1 & 65.6 & 89.7 & 94.6 \\
2 & 2.7 & 46.8 & 76.9 & 94.0 \\
3 & 2.7 & 20.5 & 83.5 & 93.7 \\
4 & 2.6 & 17.6 & 90.7 & 92.2 \\
5 & 2.4 & 17.6 & 92.2 & 88.8 \\
6 & 2.4 & 15.2 & 92.0 & 89.1 \\
7 & 2.3 & 14.9 & 92.4 & 88.1 \\
8 & 2.3 & 13.7 & 93.1 & 87.8 \\
9 & 2.1 & 12.3 & 93.7 & 87.7 \\
10 & 2.1 & 12.1 & 92.0 & 88.1 \\
\hline
\end{tabular}

are performed on virgin sample, after one cycle and after two cycles. The variation in $\tan \delta$ versus temperature is shown in Fig. 9 and the values of the glass transition temperature $T_{g}$ are given in Table 6.

According to Fig. 9, $\mathrm{T}_{\mathrm{g}_{-} 1}$ (corresponding to the soft phase SBS) falls continuously from $-82{ }^{\circ} \mathrm{C}$ for the virgin sample to $-86^{\circ} \mathrm{C}$ at the end of the second cycle. In contrary, $\mathrm{T}_{\mathrm{g} \_2}$ (corresponding to the hard phase PCL) grows from -42 ${ }^{\circ} \mathrm{C}$ for the virgin sample to $-37^{\circ} \mathrm{C}$ at the end of the second cycle. This outcome means that the gap between both peaks widens. By increasing the number of SM cycles, the blend immiscibility rises. It can be noticed that the sample does not keep the same physical properties even when it regains almost its initial shape after each cycle.

These results also show that, despite the change in properties $\left(E, \sigma, \mathrm{T}_{\mathrm{g}}\right)$, the recovery is realized in the same way. The speed of recovery (the slope of the recovery rate
Table 6 The value of $\mathrm{T}_{\mathrm{g}}$ for different shape memory cycles

\begin{tabular}{lll}
\hline & $\mathrm{T}_{\mathrm{g}_{-} 1}\left({ }^{\circ} \mathrm{C}\right)$ & $\mathrm{T}_{\mathrm{g}_{-} 2}\left({ }^{\circ} \mathrm{C}\right)$ \\
\hline Virgin & -82 & -42 \\
Cycle 1 & -85 & -39 \\
Cycle 2 & -86 & -37 \\
\hline
\end{tabular}

curve, Fig. 8) of different cycles are the same. It appears that decreasing the stiffness of the polymer has no effect on this parameter. This shows that despite the drop of the modulus during the 10 cycles, the hard phase of the polymer remains rigid enough to ensure the fixation and the recovery during the temporary state. The recovery of the initial shape depends on two sources of energy:

- Thermal energy which will generate the necessary molecular movement.

- Mechanical energy (internal stress) stored in the structure of the material which will play the role of the driving force.

It should be noted that the thermal energy supplied to the material could be easily controlled. While, the driving force is more difficult to control. The relation between this force (stress) and the displacement (strain) during the recovery will be investigated.

\section{Driving force}

During recovery, the sample is submitted to a driving force which allows it to regain its permanent shape. When the shape memory polymers are in its initial shape, the internal stress is very low. After deformation, the residual stress rises
Fig. 9 DMTA analysis at different shape memory cycles

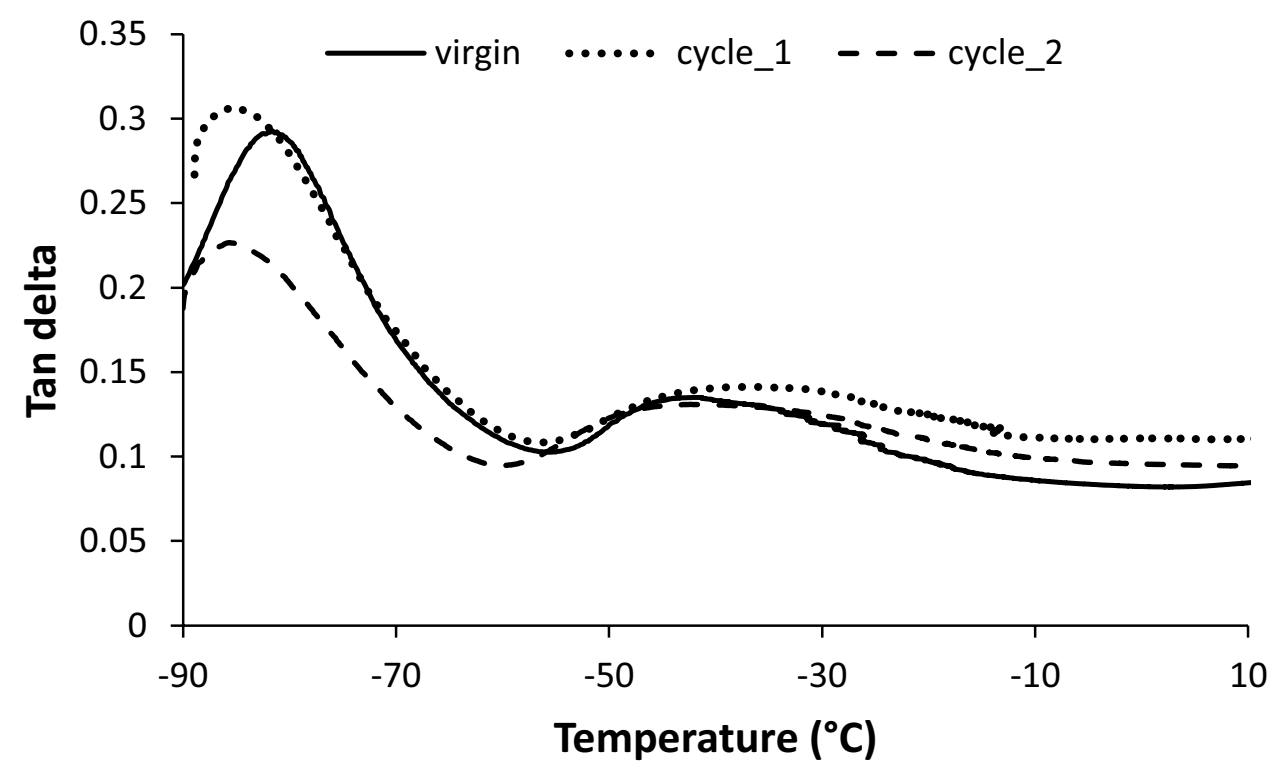




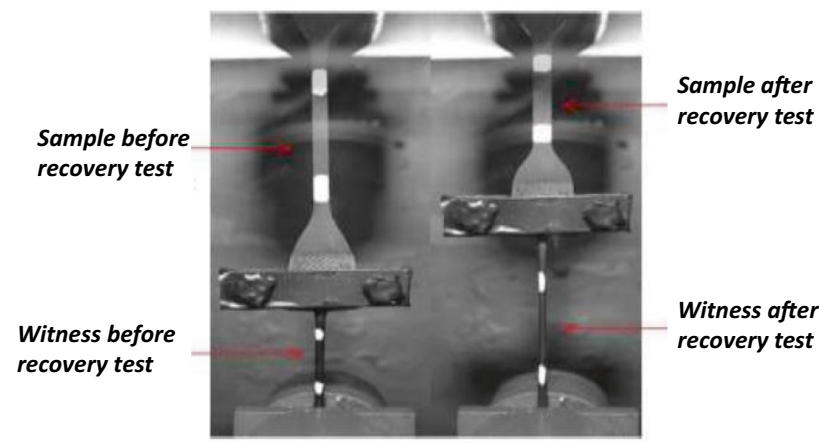

Fig. 10 Sample attached to a witness used during recovery

and then is stored in the structure during the fixing step. By heating again, the SMP at the temperature above its glass transition temperature, these residual stresses are released. As a result, the sample regains its initial shape. Accordingly, this internal residual stress is the driving force; responsible of recovery [4-6].

During the recovery test all parameters vary with time. There is practically any standard mechanical test equivalent to this test:

- In the recovery test, the length of the sample shortens. However, it cannot be considered as a compression test because the rate of deformation is not constant.

- The recovery test is not a creep test. Contrary to the creep test, the stress (driving force) is not constant. When the temperature is higher than the glass transition temperature, it drops until reaching zero or a stable minimum value.

- The recovery test is also different from the relaxation test where the deformation is constant and only the stress decreases during the time in an isothermal condition.

Fig. 11 Witness tensile test
- Furthermore, as it was explained before, the recovery test of the blend under study cannot be performed in an isothermal condition. During the recovery test, the temperature is controlled with a rate of $1 \%$ min.

- In the recovery test, it is not difficult to measure the strain (recovery) but it is not so easy to follow the variation of internal residual stresses (driving force).

Because of all above raisons, it is not possible to establish the stress-strain curves using different standards mechanical tests. In this study, original method has been used to establish the stress-strain curve related to the recovery test.

In this method, a witness with known properties is attached to the (PCL/SBS) blend sample and deformed during its recovery (Fig. 10). When a heating rate of $1^{\circ} \mathrm{C} /$ min is applied, the sample begins to regain its initial form. This deformation will be transmitted to the witness that will be deformed simultaneously. Hence, the evolution of both deformations can be simultaneously monitored during time. In fact, the driving force responsible for the sample recovery is at the same time responsible for the witness deformation.

To determine the stress-strain evolution of the blend during the recovery, it is first necessary to realize a tensile test on the witness alone, as presented in Fig. 11. This test depicts the evolution of stress versus strain of the witness. In the following section, this test will be called test- 1 .

Next, the witness is attached to the free extremity of the SMP stretched sample. The recovery test started by heating the component. While the SMP size is decreasing, the witness length is growing as shown is Fig. 12. In the following section, this test will be called test- 2 .

As both materials do not have the same characteristics, they are not going to deform in the same way. To obtain the stress strain evolution of the SMP during the recovery test, the following steps should be respected: 
Fig. 12 Strain evolution: a SMP sample and $\mathbf{b}$ witness

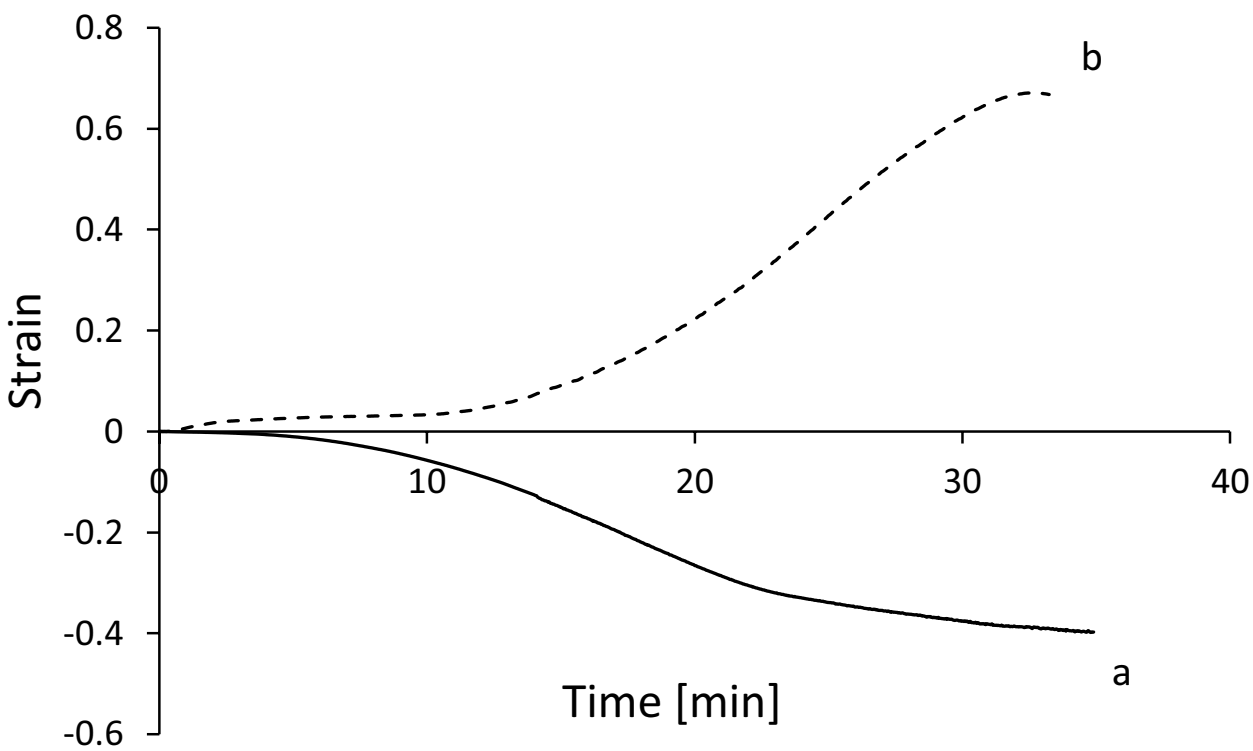

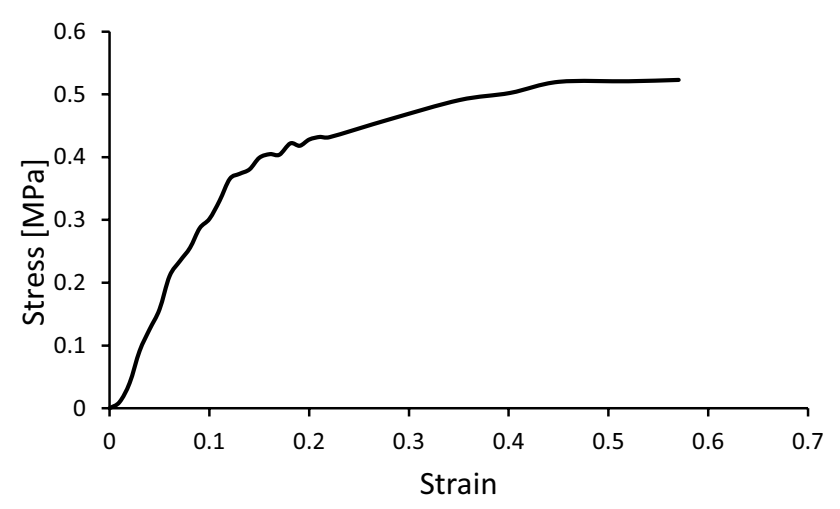

Fig. 13 Stress-Strain curve for controlled temperature recovery $\left(1^{\circ} \mathrm{C} /\right.$ $\min )$.

- At a specific time ' $t$ ', the witness strain value is picked up from test- 2 and its corresponding stress value is fetched in the test-1.

- As sample and witness remains tied during recovery, they are submitted to the same force. Yet, this force value will be divided by sample section to obtain its stress value.

- Then, this stress value will be coupled with the strain value from curve 'a' on Fig. 12 at the same specific time ' $t$ '.

- The stress strain evolution during the recovery is then obtained and shown on Fig. 13.

\section{Conclusion}

In this work, an innovated immiscible mixture consisting of $40 \%$ PCL and $60 \%$ SBS has been introduced and studied. This blend constitutes a shape memory polymer due to its ability to recover its initial shape under thermal trigging. The capacity of shape change and recovery could be explained by the presence of two different phases, hard and soft. The PCL presents the hard phase and acts as connection points that maintain the permanent shape. The SBS represents the soft phase made by flexibles chains that are sensitive to stimulus and ensure the shape change.

The shape memory tests indicate that the mixture presents a PSME. It was shown that the temperature has an influence on the mechanical and shape memory properties. Indeed, at a high temperature, the polymer has high molecular mobility and can be easily deformed. Furthermore, during the recovery phase, the more the temperature raises, the more the recovery rate increases.

For the multi-cycle memory tests, it was demonstrated that the stiffness decreases after every cycle. Besides, the recovery rate grows from the first cycle until the fifth where it stabilizes in the tenth cycle at $92 \%$. The same phenomenon has been observed for the fixation rate, where it stabilizes in $88 \%$. The blend will not get its mechanical and viscoelastic properties back when it returns to its initial form. It can be due to irreversible microscopic changes. These properties, which depends on the microstructure, have a mechanism of evolution different from that of the shape memory effect.

Finally, the driving force responsible for the recovery is indeed the internal stresses introduced into the shape memory polymer during the tensile test, stored during the fixing step and released during the recovery.

An original method using a witness with known properties has been used to establish the stress-strain curve during recovery.

Studying the micro-structural changes responsible for the memory effect and the material degradation effect on the property of the shape memory present a good continuity to this work. 
Funding No funding was received to assist with the preparation of this manuscript

\section{Declarations}

Research involving human and animal participants The article follows the guidelines of the Committee on Publication Ethics (COPE) and involves no studies on human or animal subjects.

Consent to participate Not applicable. The article involves no studies on humans.

Consent to publish Not applicable. The article involves no studies on humans.

Competing interests The authors declare that they have no competing interests.

Conflict of interest The authors declare that they have no conflict of interest.

\section{References}

1. Lendlein A, Kelch S (2002) Shape-memory polymers Angew. Chem. Int. 41:2034-57

2. Behl M, Lendlein A (2007) Shape-memory polymers. Mater. Today 10:20-8

3. Leng J, Lu H, Liu Y, Du S (2008) Conductive nanoparticles in electro activated shape memory polymer sensor and actuator SPIE: Proc. Nanosensors and microsensors for bio-systems (San Diego, CA, USA) pp 6931-8.

4. Abdallah-Elhirtsi S, Fitoussi J, Rashmi BJ, Prashantha K, Farzaneh S, Lacrampe MF, Krawczak P, Tcharkhtchi A (2015) Study of partial shape memory effect of polymers by multicycle tests Polym. Compos. 36:1145-51

5. Tcharkhtchi A, Abdallah-Elhirtsi S, Ebrahimi K, Fitoussi J, Shirinbayan M, Farzaneh S (2014) Some New Concepts of Shape Memory Effect of Polymers. Polymers 6:1144-63

6. Farzaneh S, Fitoussi J, Lucas A, Bocquet M, Tcharkhtchi, (2013) A Shape memory effect and properties memory effect of polyurethane. J. App. Polym. Sci. 128:3240-49

7. Tadaki T, Otsuka K, Shimizu K (1988) Shape Memory Alloys. Annu. Rev. Mater. Sci. 18:25-45

8. Lendlein A, Langer R (2002) Biodegradable, elastic shapememory polymers for potential biomedical applications Science 96:1673-6.
9. Wache H M, Tartakowska D J, Hentrich A, Wagner M H (2004) Development of a polymer stent with shape memory effect as a drug delivery system J. Mater. Sci: Mater. Med. 14109-12.

10. Hu JL, Ding XM, Tao XM (2002) Shape memory polymers and their applications to smart textile products. J. China Textile Univ. 19:89-93

11. Russel D A, Hayashi S, Yamada T (1999) The potential use of memory film in clothing: Proc. techtextil symposium-new protective textiles (Frankfurt, Germany) pp 1-5

12. Karger-Kocsis J (2008) Recent advances in shape memory polymers and composites. J. Mater. Sci. 43:254-269

13. Xie T (2011) Recent advances in polymer shape memory Polymer 52:4985-5000

14. Hu J (2012) Recent advances in shape-memory polymers: Structure, mechanism, functionality, modeling and applications Prog. Polym. Sci. 37:1720-63

15. Blesa Gonzalez E (2011) Etude du Polyuréthane et du blend Poly ( $\varepsilon$-Caprolactone)/Styrène-Butadiène-Styrène. Master thesis Art et Métiers ParisTech

16. Lin JR, Chen LW (1998) Study on shape-memory behaviour of polyether-based polyurethanes. I. Influence of the hard-segment content. J. Appl. Polym. Sci. 69:1563-74

17. Lin JR, Chen LW (1998) Study on shape-memory behavior of polyether-based polyurethanes. II. Influence of soft-segment molecular weight. J. Appl. Polym. Sci. 69:1575-86

18. Manandhar S (2011) Bioresorbable Polymer Blend Scaffold for Tissue engineering BSc Thesis University of North Texas

19. NF ISO 6239 (1986) Plastics-Determination of Tensile Properties by Use of Small Specimens Association Française de Normalisation (Seine-Saint-Denis, France)

20. Biron $M$ (2000) Elastomères Thermoplastiques (AM 3 400) pp $1-13$

21. Liu N, Huang WM, Phee SJ (2007) A secret garden of micro butterflies: phenomenon and mechanism. Surf. Rev. Lett. 14:1187-1190

22. Zhang H, Wang H, Zhong W, Du Q (2009) A novel type of shape memory polymer blend and the shape memory mechanism. Polymer 50:1596-1601

23. Ben Abdallah A, Gamaoun F, Kallel A, Abbas Tcharkhtchi (2020) Molecular weight influence on shape memory effect of shape memory polymer blend (poly (Caprolactone)/styrene-butadienestyrene) J. of App. Poly. Sci. e49761

24. Dimensions Des Éprouvettes Pour Essais de Traction Selon Les Normes : Thermoplastiques et Thermo-durcis. Available from: http:// www.atomer.fr/1/1_dimensions-eprouvettes-essais-de-traction.html 